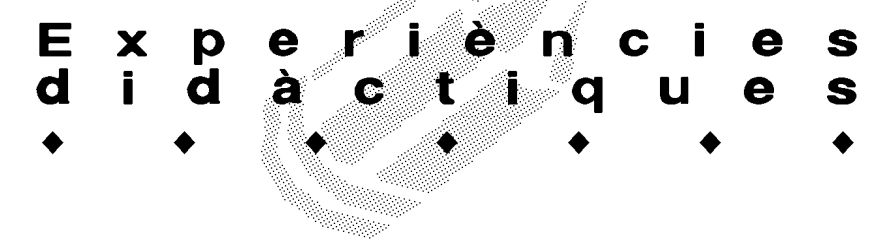

\title{
CONSIDERACIONS SOBRE EL TREBALL DE RESOLUCIÓ DE PROBLEMES A L'ESCOLA
}

\author{
Luisa Girondo Pérez. Àrea de Didàctica de la Matemàtica. URV
}

Les visions actuals de l'educació matemàtica assignen a la tasca de resoldre problemes una posició privilegiada. Això es deu a una concepció determinada del paper dels aprenentatges, que és en aquest cas accentuar el paper dels processos de producció de coneixement enfront dels processos de transmissió dels coneixements. La resolució de problemes es considera el lloc on es produeixen coneixements, és a dir, on s'apliquen les eines de què es disposa a una situació nova; aquesta transferència de coneixement, en adaptarse a una nova situació, ampliarà en alguna mesura el significat, i per tant, es pot considerar que es produeix coneixement nou.

A partir d'aquí, els problemes no poden ser simples exercicis en els quals "aplicar" els coneixements adquirits prèviament; sinó que han de ser el lloc de "producció de coneixement significatiu per part de qui aprèn". D’aquí es deriva que presentar als estudiants situacionsproblema que els motivin i per a les quals es necessiten idees matemàtiques noves és una tècnica didàctica adequada. El professor presenta així les matemàtiques com una cosa útil per a entendre certs aspectes de la realitat, i l'alumne, al tractar de resoldre la situació, avança en la construcció del seu esquema mental i, si és convenientment guiat, recrea el coneixement matemàtic formal. Es pot dir que "fa matemàtiques". En

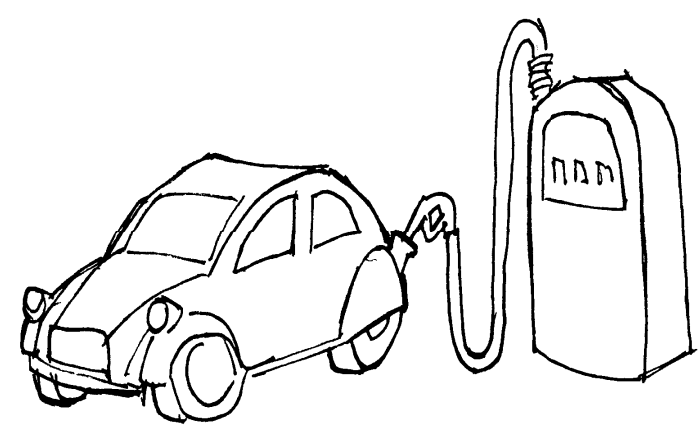

Quants litres de gasolina es poden posar amb 5000 pts, si cada litre val 127 pts?

Fig. 1. Situació quotidiana que dóna sentit aplicatiu a les operacions aritmètiques paraules de H. Freudenthal, es tracta d'ajudar els alumnes a "matematitzar" l'entorn. I per "matematitzar" entén l'autor "l'activitat que el alumne desenvolupa per organitzar la seva experiència i que comporta desenvolupar

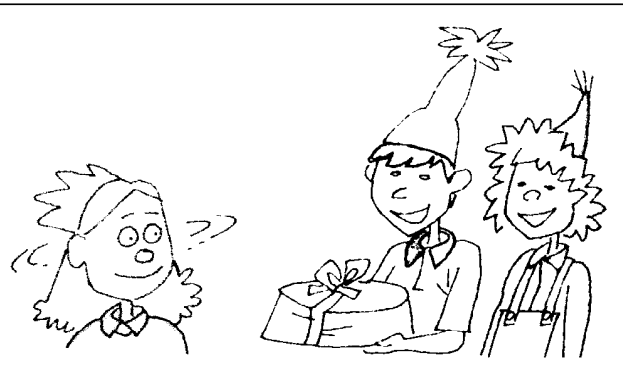

Cal preparar la festa de final de curs de la classe. Es farà un berenar amb entrepans i begudes per a tothom...

Quants diners posarà cada alumne?

Fig. 2. Situació a matematitzar. Deduir nova informació

procediments intuïtius per resoldre problemes, creació de notació simbòlica i construcció d'objectes mentals (que més tard seran conceptes)".

Tot i que derivar l'aprenentage de les matemàtiques per la matematització de "situacions adequades" és una cosa encara llunyana en la nostra escola actual, la idea de veure el procés d'aprenentage en paral-lel a un procés de resolució de problemes és força atractiva de cara a la pràctica escolar.

\section{Però... què és un problema?}

Lester diu que un problema és "una situació que un individu o un grup vol o necessita resoldre sense tenir un camí ràpid i directe que el porti a la solució".

Aquesta descripció val tant per als problemes en el sentit quotidià del terme: "Haig de ser a l'escola a les $9 \mathrm{i}$ són tres quarts i el meu cotxe no arranca... què faig?" No hi ha problema si al costat tinc un altre cotxe o si algú em pot acompanyar... Com per als problemes que proposem als alumnes a la classe de matemàtiques.

Però una situació en si mateixa no és un problema, sinó que el que li dóna caràcter problemàtic - segons la definició de Lester- és no tenir un camí clar per sortir- 


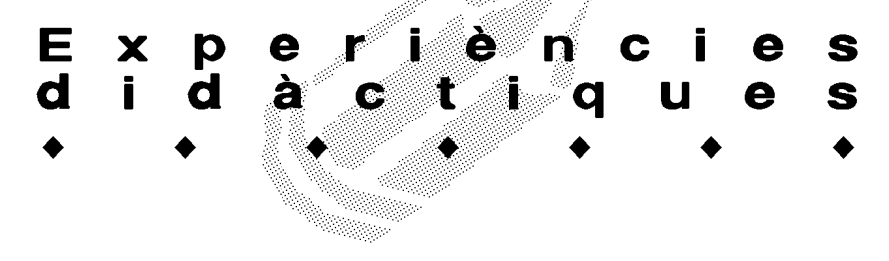

se'n. Per tant, una situació és o no problema en funció del resolutor.

Només hi ha un que menteix. Qui és?

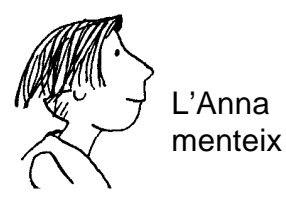

Jo dic la veritat
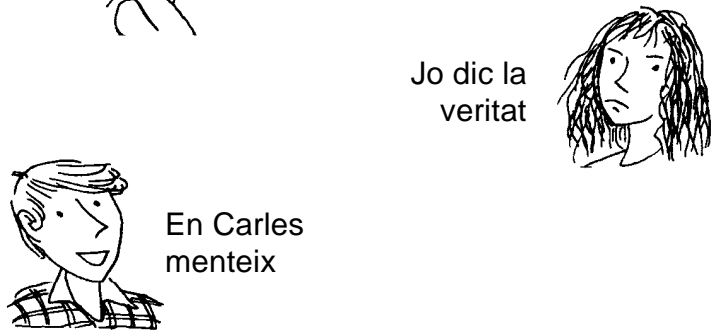

En Carles menteix

Fig. 3. Problema de lògica

És el que s'enfronta a la tasca el que activa processos de recerca, d'analogia, emet hipòtesis... si la veu com un problema, o passa a executar un pla que ha vist de manera immediata si la tasca és un simple exercici.

\section{Els problemes a la classe de matemàtiques}

Si ens situem en un marc curricular determinat, cal preguntar-se: per què hem de fer problemes a la classe de matemàtiques?

Es poden trobar raons diverses, però la més important és que les matemàtiques no són una màquina de la qual és suficient saber com funciona, sinó que es tracta d'un saber que es construeix personalment (o s'ha construilt socialment) com a resposta a problemes que es plantegen (o s'han plantejat històricament) i que a través d'un procés reflexiu i d'abstracció progressiva dota a l'individu (o a la societat) d'instruments intel-lectuals necessaris per a entendre $\mathrm{i}$ actuar en el medi físic i social en què viu.

Quan ens ocupem d'alumnes en els primers nivells d'escolaritat, a més de procurar l'adquisició d'eines generals que la resolució de problemes implica, ha d'haverhi lògicament una atenció acurada a les eines bàsiques que el currículum selecciona. És el cas de la utilització del llenguatge numèric i de les operacions elementals de l'aritmètica, que ocupa una part important del programa escolar.

Amb aquesta visió podem dir que els problemes, d'una banda, seran les "situacions " que caldrà matematitzar (aïllar, quantificar, relacionar, esquematitzar...) i que ens serviran de marc per fer raonaments. Són les situacions que serveixen de base a l'aprenentatge de la utilització del llenguatge numèric. I de l'altra banda, els problemes seran els llocs on aplicar els coneixements ja adquirits a situacions noves $i$, per tant, on es posarà de manifest la "transferència" d'allò que se sap, s'ampliaran significats i se'n veurà la utilitat.

A mesura que els alumnes van adquirint eines bàsiques -expressió simbòlica, llenguatge numèric, capacitat lògica- és convenient presentar situacions més complexes en les quals anar entrenant estratègies més sofisticades, i fins i tot estratègies de resolució de problemes: fer una hipòtesi i posar-la a prova; transformar el problema en un altre més senzill; suposar el problema resolt i anar de la solució a les dades...

Per tant, a l'hora de seleccionar situacions-problema per presentar als alumnes caldria considerar a quin d'aquests tres objectius respon:

1. Situació-problema dirigida a introduir noves nocions. (És la idea del problema com a procès d'aprenentatge).

Exemple: L'objectiu és iniciar la idea de producte com a suma repetida.

Situació: "Avui farem un treball en què cal enganxar uns adhesius a unes cartolines. Cada nen tindrà una cartolina i haurà d'enganxar 6 adhesius. Si a cada taula hi ha 4 nens, quants adhesius hem de deixar damunt de cada taula perquè es pugui fer el treball?"

Alguns nens faran: $6+6+6+6$.

Altres diran: $12+6+6$.

Altres dibuixaran 4 paquets de sis cartolines i comptaran.

Una posada en comú de les solucions aportades farà veure que hi ha moltes maneres de resoldre el problema, que fer un dibuix-esquema ens pot ajudar a entendre el que passa... i finalment es dirà que 4 vegades 6 es pot escriure com a $4 \times 6$ i que això és multiplicar.

Aquesta manera de procedir és molt aconsellable. El nen és el protagonista de l'aprenentatge, a poc a poc

Quants triangles diferents pots representar en aquest geoplà?

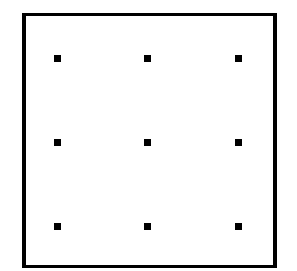

Fig. 4. Iniciació al treball sistemàtic, entès com una petita investigació 


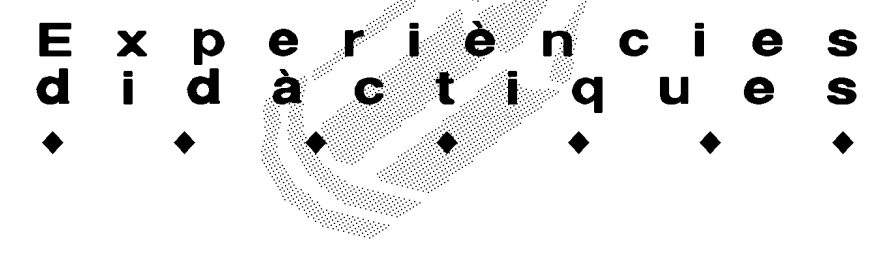

va agafant confiança en el seu raonament i en la seva capacitat per sortir-se de les situacions-problema. El paper del nou instrument que es presenta en aquest cas - una primera idea de producte-, es veurà com una eina més potent per fer les coses de manera més directa.

El treball del mestre és molt important en aquesta manera de procedir. Ha de triar les situacions adequades; una situació serà adequada no solament perquè es puguin establir les relacions que permetin mostrar un determinat concepte matemàtic, sinó perquè els alumnes la vegin interessant. Ha de ser pròxima al seu camp d'experiència i ha de tenir una dificultat apropiada al seu nivell intel-lectual.

L'aprofitament pedagògic vindrà donat també per la dinàmica que s'estableixi a la classe. Aquestes situacions es presten a treballar primer de manera individual o en petit grup, i fer després una posada en comú en gran grup.

2. Situació-problema dirigida a aplicar les eines adquirides i veure els límits d'aplicació que tenen.

Es proposaran situacions similars, però no idèntiques. L'alumne haurà d'analitzar la situació que es presenta; identificar la informació necessària per respondre el que es pregunta; veure quines relacions lògico-matemàtiques lliguen les dades i el que es demana; procedir a realitzar càlculs o fer hipòtesis de solucions; finalment, conprovar si el resultat obtingut té sentit.

També en aquest cas cal fugir de presentar situacions estereotipades. És important que l'alumne hagi de prendre alguna decisió, que no sigui un problema tancat. Les situacions més elementals poden tenir un excés de dades, o demanar cercar les dades

Sense fer cap operació, raona quina fracció del quadrat representa la figura tramada.

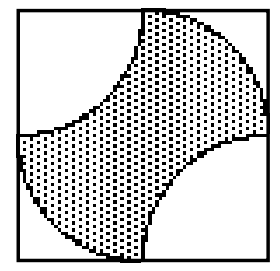

Fig. 5. Problema espacial, del camp de la geometria

en algun Iloc. Han d'estar presentades de manera entenedora. Cal valorar les dificultats de llenguatge que puguin tenir els alumnes i ajudar la presentació amb dibuixos, esquemes, etc.
3. Situacions-problema més complexes en les quals cal afinar la capacitat creativa i aplicar raonaments més elaborats.

La complexitat de la situació presentada és deguda a la relació que cal establir entre la informació que es dóna i el que es pregunta; són les relacions que s'estableixen les que determinen la dificultat, no la situació en si mateixa.

Exemple a): Un avi que té 75 anys parla amb el seu nét te 9 anys i l'avi li diu: - Mira, quan tu tinguis els anys que té ara el teu pare, ell serà de la meva edat.

Quants anys té el pare del nen?

a) Quantes cadires hi ha en una classe que té 4 fileres de 6 cadires cada una?

b) En Miquel té 12 anys i el seu pare el triplica en edat. Quants anys té el pare d'en Miquel?

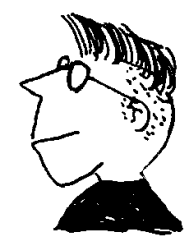

Fig. 6. Seqüenciació dels problemes en funció de la seva dificultat

Exemple b): Quantes cadires i quants alumnes hi ha en aquesta classe?

El dia de la reunió de pares han vingut 15 pares més que alumnes hi ha a la classe i s'han hagut de portar 8 cadires d'una altra sala; així i tot, 3 pares s'han assegut en taules. La mestra utilitzava la seva cadira.

L'endemà van fer una reunió de mestres en aquesta classe; van assistir 23 mestres, i com que encara hi havia a la classe 4 cadires que pertanyien a l'altra sala, sobraven 8 cadires.

\section{Tipologia de problemes per a Primària}

A més de considerar la funció del problema en el currículum, que porta a la classificació anterior, nosaltres hem considerat útil l'agrupació de problemes que són abordables a Primària en aquestes cinc categories:

\section{Problemes aritmètics.}

Situacions quotidianes que donen sentit aplicatiu a les operacions aritmètiques. Seran d'una etapa o de diverses i també d'una operació o d'operacions combinades. (fig. 1).

Metodologia: en funció del lloc en el currículum.

Situacions a matematitzar.

Situacions reals a aïllar i descriure en termes quantitatius. Deduir informació nova... (fig. 2).

Metodologia: treball en grup i posada en comú posterior. 


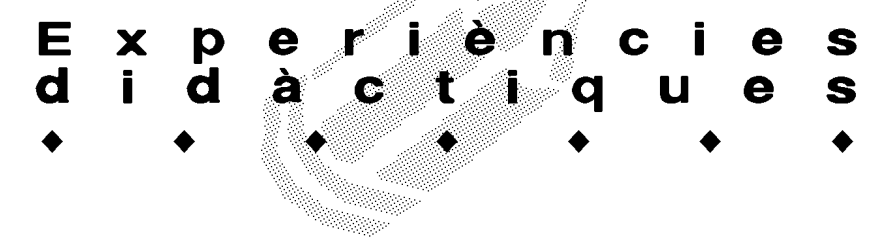

Escriu el text d'un problema a partir de la informació que hi veus.

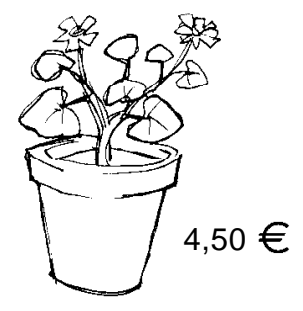

$$
10 €
$$

$3,75 €$

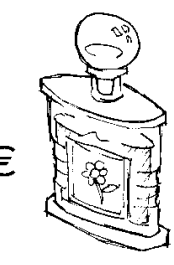

Fig. 7. Escriure un problema a partir d'informació gràfica

Problemes de lògica i jocs matemàtics.

Tenen per objectiu desenvolupar estratègies de pensament.

Metodologia: Realització individual o en petit grup.

Competició. Problema del mes... (fig. 3).

Investigacions.

Iniciació de treball sistemàtic i fer petites generalitzacions.

En general, són situacions del camp de la matemàtica, que s'han de preparar per a alumnes d'aquests nivells. (fig. 4).

Metodologia: Treball en gran grup o grup mitjà.

Problemes espacials.

Situacions del camp de la geometria que no estarien recollides en els apartats anteriors. (fig. 5).

Metodologia: En funció del problema.

\section{El procés de resolució de problemes}

Per procés de resolució d'un problema caldria entendre, des d'un punt de vista cognitiu, l'activitat mental que l'alumne posa en funcionament des que assumeix que té davant seu un problema (una situació en què apareixen unes dades, unes incògnites o una meta per aconseguir, i unes relacions significatives entre elles) fins que el dóna per finalitzat.

Molts investigadors han estudiat el procés de resolució de problemes i el descriuen per fases. La descripció més acceptada és la de Polya, que suposa un "resolutor ideal" en les següents fases: 1) comprendre el problema; 2) concebre un pla d'execució; 3) executar el pla; 4) valorar la solució obtinguda.

No cal prendre's al peu de la lletra aquest procés, donat que no es tracta de "resolutors ideals" ni es pot "algorismitzar" el procés de resolució. No obstant això, sí que són importants algunes fases que aquest model descriu. A continuació analitzem breument cada una d'elles.
Comprendre el problema.

Si el problema es presenta de manera escrita (la qual cosa es necessària com a marc escolar!), la fase de lectura és molt important als primers nivells donat que poden sorgir paraules 0 estructures sintàctiques desconegudes per l'alumne; la fase de comprensió, molt lligada a la de lectura, implica moltes vegades reformular el problema; en altres paraules, fer una dramatització de la situació o fer un dibuix que la representi.

És veritat que alguns alumnes volen estalviar-se llegir el problema... però també és cert que en algunes situacions no n'hi ha prou amb un simple "torna'l a llegir".

És quasi bé imprescindible que el problema sigui "interessant" per a l'alumne. Que desperti en ell ganes de resoldre'l... Per això resulten adequats els problemespassatemps (solen tenir poc text i motiven els alumnes).

Encercla l'operació què cal fer per contestar.

Hem fet $140 \mathrm{~km}$ i encara ens en falten 78 per arribar al destí. De quants $\mathrm{km}$ era el viatge?

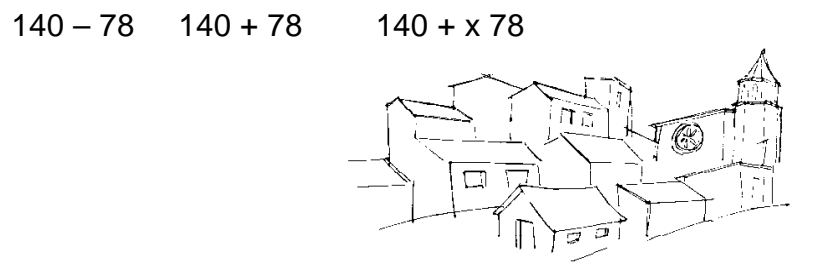

Fig. 8. Triar l'operació que resol una situació

\section{Planificar com es resoldrà.}

Abans de procedir a fer operacions ràpidament, és important parar-se a pensar què es farà, principalment si el procés es de diverses etapes. Es pot fer que els alumnes expliquin quin procés seguiran per deduir la informació que es demana a partir de la informació que es té.

Executar el pla previst.

En moltes ocasions aquesta execució portarà a fer uns càlculs. Cal decidir com fer-los: mentalment, càlcul vertical, amb calculadora... També - a partir d'una determinada edat- es pot valorar si és necessària una resposta exacta o aproximada, ja que això fixarà el métode de càlcul.

Quan es tracta de problemes aritmètics, donat que són els primers problemes (matemàtics) amb els quals es troba l'alumne i que aquest procés va essent paral-lel al d'adquisició de les eines bàsiques d'aquest llenguatge (la noció de número, la noció d'operació, juntament amb 


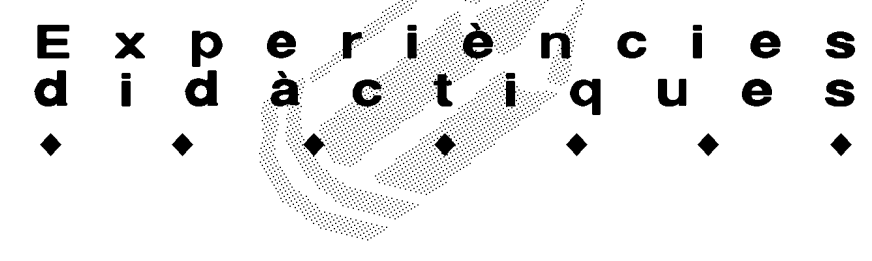

la comprensió lectora, a interpretar la realitat a partir de gràfics, etc.), és convenient indicar als alumnes si el problema es pot resoldre per mètodes informals o si cal utilitzar les eines formals adquirides (producte, resta, etc.).

\section{Valorar la solució obtinguda.}

Aquesta fase fa referència a l'explicitaciò de la solució del problema; pot anar lligada a l'última de revisió o comprovació, en què es torna a mirar tot el problema des del començament. És el resultat esperat? És lògic? (en el sentit de creïble). Podríem arribar a la solució per un altre camí?

\section{Alguns consells específics per treballar els proble- mes a l'etapa de Primària}

De les investigacions en el treball de problemes es dedueix que molts alumnes tenen moltes dificultats en la resolució de problemes, ja que, com es pot deduir del que hem vist fins ara, en el procés de resolució intervenen

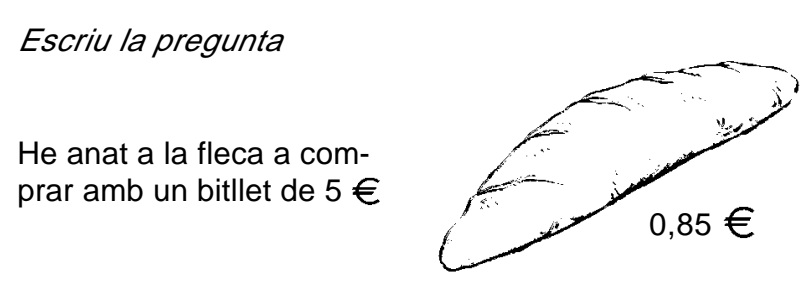

Sol. $\quad 5-(3 \times 0,85) €$

Fig. 9. Escriure la pregunta a partir de la solució aritmètica

molts factors, i no cada un aïllat, sinó tots relacionats, cosa encara més complexa. Us proposem algunes estratègies d'ajuda.

- En primer lloc, és imprescindible decidir quins problemes farem i per què.

- Evidentment, caldrà presentar i seqüenciar per dificultat els problemes. Situacions que donen diferents significats a les operacions aritmètiques. $A$ vegades els textos porten una bona seqüenciació, pero d'altres no. Són equivalents els significats de producte en les situacions de la fig.6?

- Presentar situacions obertes a fi de millorar la interiorització de la situació per part de l'alumne - sembla que creix l'interès - i també això ens permet atendre la diversitat.

Exemple: En una classe són 22 alumnes. Hi ha més nenes que nens. Quants nens hi ha?

Per a algun alumne serà suficient que doni una solució; un altre en donarà tres o quatre i algú veurà totes les possibilitats...

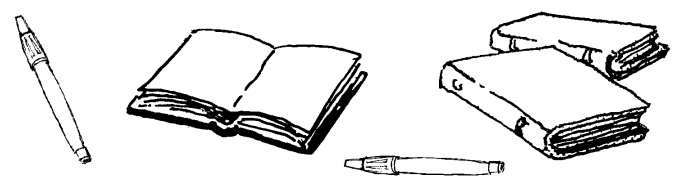

He comprat un llibre i dos retoladors. Quant m'han tornat de canvi?

Fig. 10. Determinar quina informació es necessita per resoldre el problema

- Exercitar aspectes parcials dels problemes:

- Donada una situació en forma gràfica, escriure un problema (fig. 7).

- Donada una situació amb una pregunta, triar l'operació que la resol (fig. 8).

- Donada una situació quantitativa i una operació, escriure la pregunta (fig. 9).

- Donat un problema, només verbalitzar com es faria.

- Donat un problema, preparar el procés de càlcul perquè ho faci el "calculista".

- Fer esquemes que representin situacions.

- Donat un esquema, escriure un problema que sigui adequat a ell.

- Donada una situació i una pregunta, determinar la informació necessària (fig. 10).

- Amb una informació donada, escriure totes les preguntes que es poden respondre.

- Matematitzar situacions viscudes.

- Proposar proporció adequada de les cinc tipologies:

- Aritmètics.

- Situacions quotidianes.

- Problemes passatemps (lògics, numèrics i espacials).

- Iniciar investigacions (pautes).

- Problemes espacials (geometria).

\section{Bibliografia consultada}

CERDAN, F. i PUIG, L. Problemas aritméticos ecolares. Editorial Síntesis. Madrid. 1988.

D’AMORE, B. La Solución de Problemas. Editorial Síntesis. Madrid. 1997.

GIRONDO, L. Factors a considerar en treballar els problemes a Primària. «Perspectiva Escolar» 232 (1998). 